\title{
Sedimentary records of polycyclic aromatic hydrocarbons (PAHs) in remote lakes across the Tibetan Plateau ${ }^{\text {it }}$
}

\author{
Ruiqiang Yang a, Ting Xie ${ }^{\mathrm{a}}$, An Li ${ }^{\mathrm{b}}$, Handong Yang ${ }^{\mathrm{c}}$, Simon Turner ${ }^{\mathrm{c}}$, Guangjian Wu ${ }^{\mathrm{d}}$, \\ Chuanyong Jing a, * \\ a State Key Laboratory of Environmental Chemistry and Ecotoxicology, Research Center for Eco-Environmental Sciences, Chinese Academy of Sciences, P.O. \\ Box 2871, Beijing 100085, China \\ b School of Public Health, University of Illinois at Chicago, Chicago, IL 60612, United States \\ ${ }^{\mathrm{c}}$ Environmental Change Research Centre, University College London, Pearson Building, Gower Street, London WC1E 6BT, UK \\ ${ }^{\mathrm{d}}$ Institute of Tibetan Plateau Research, Chinese Academy of Sciences, Beijing 100101, China
}

\section{A R T I C L E I N F O}

\section{Article history:}

Received 12 January 2016

Received in revised form 25 March 2016

Accepted 26 March 2016

Available online 7 April 2016

\section{Keywords:}

Long-range atmospheric transport (LRAT)

Sediment

Historical trend

PAHs

\begin{abstract}
A B S T R A C T
Sediment cores from five lakes across the Tibetan Plateau were used as natural archives to study the time trends of polycyclic aromatic hydrocarbons (PAHs). The depositional flux of PAHs generally showed an increasing trend from the deeper layers towards the upper layer sediments. The fluxes of PAHs were low with little variability before the 1950s, and then gradually increased to the late 1980s, with a faster increasing rate after the 1990s. This temporal pattern is clearly different compared with those remote lakes across the European mountains when PAHs started to decrease during the period 1960s-1980s. The difference of the temporal trend was attributed to differences in the economic development stages and energy structure between these regions. PAHs are dominated by the lighter $2 \& 3$-ring homologues with the averaged percentage over $87 \%$, while it is notable that the percentage of heavier $4-6$ ring PAHs generally increased in recent years, which suggests the contribution of local high-temperature combustion sources becoming more predominant.
\end{abstract}

(c) 2016 Elsevier Ltd. All rights reserved.

\section{Introduction}

The Tibetan Plateau (TP) stretches nearly $1000 \mathrm{~km}$ north-tosouth and $2500 \mathrm{~km}$ east-to-west in east-central Asia, with the average elevation exceeding $4500 \mathrm{~m}$. Similar to the polar regions, most parts of the TP are remote and inaccessible, which has led to the presumption of its pristine status. However, the TP is located at low latitude, and surrounded by the rapidly industrializing countries of South and Southeast Asia. Semi-volatile persistent pollutants released from the surrounding source regions can migrate to TP by long-range atmospheric transport (LRAT). In addition, fast growth in population, tourism and gross industrial activities in localities within the TP in the past decades may have adversely impacted the environment, altering its previously pristine interior ecosystem.

The lakes on the Plateau differ from lakes in lowlands. The

\footnotetext{
This paper has been recommended for acceptance by Eddy Y. Zeng

* Corresponding author.

E-mail address: cyjing@rcees.ac.cn (C. Jing).
}

inputs of chemical pollutants to alpine lakes are generally predominated by atmospheric deposition away from direct input (Juttner et al., 1997). Increasingly enhanced global warming in recent decades has accelerated the melting of glacier and frozen soil at high altitude, releasing previously trapped chemical pollutants which may consequently be flushed into alpine lakes (Bogdal et al., 2009). In addition, the post-depositional sediment mixing in deep alpine lakes is relatively limited (Fernandez et al., 2000). The sediments in such lakes are regarded as sentinel indicators of atmospheric pollution due to the lack of local pollution sources (Rose and Rippey, 2002; Bettinetti et al., 2011).

Polycyclic aromatic hydrocarbons (PAHs) are ubiquitous contaminants. The population growth and industrialization in surrounding areas of the TP have also inevitably increased the releases of PAHs from various combustion processes. The depositional chronology of these chemicals as recorded in relatively undisturbed sediments of alpine lakes in the TP can be used as geochemical markers of economic and social development impacts (Han et al., 2015). Yang et al. (2010) reconstructed mercury pollution using lake sediments from the TP. Cheng et al. (2014) reported time 
trends of OCP pollution by analyzing sediments from three lakes in the central TP. Wang et al. (2010) and Han et al. (2015) reconstructed PAH pollution in Lake Qinghai of the northern TP. These studies documented that sediment of the TP could archive important environmental information about past anthropogenic influence. However, the sedimentary PAH data across the TP, especially in the southern and central TP is so far very limited.

The basic hypotheses of the present study are that sediment contamination of lakes in the TP is associated with the industrialization and human activities of major Asian countries, and that over the past three decades, the rapid economic development and population growth within the TP have contributed to the overall burden of pollutants in the environment. In this study, a total of 157 samples from five sediment cores were analyzed for PAHs. The objectives were to reveal the spatial patterns along a southwest-tonortheast transect across TP, reconstruct the deposition history, and gain insights on sources of the PAHs in the sediments.

\section{Materials and methods}

\subsection{Study area and sampling}

Five lakes were selected across a southwest-to-northeast transect: Peiku Co, Nam Co, Cuo E, Cuo Na and Keluke Lake (Fig. 1). All the lakes are remote and far from urban or agricultural pollution sources and are covered annually with ice for at least several months. All the studied lakes are freshwater except for Cuo E, which is brackish with salinity of $892 \mathrm{mg} / \mathrm{L}$ in $\mathrm{Cl}^{-}$(Lami et al., 2010). Keluke is a closed basin in the semi-arid, grassland-steppe climate zones in the northeast TP with no river flowing in or out of the lake. Nam Co and Peiku Co lakes have glaciers in their catchments (Lami et al., 2010). Peiku Co is a typical tectonic lake caused by the uplift of Himalayan Mountains at the southern edge of the TP, and precipitation as well as glacier melt water is the main water supply (Nie et al., 2013). The latitude, longitude, and altitude of the lakes as well as the surface areas and depths are given in Table 1.
Sediment cores were collected in August 2006 and 2007. A HTH gravity corer with an $8.5 \mathrm{~cm}$ inner diameter polycarbonate tube was used to collect sediment cores at adjacent locations within $3 \mathrm{~m}$ of each other in each lake. Cores were collected from the deepest part of the lakes, except the two from Nam Co and Peiku Co, where they were taken from the shallower sub-basins. One core from each site was assigned for organic pollutants analyses in this study. The length of the cores ranged from 24 to $43 \mathrm{~cm}$ (Table 1). The core was sectioned onsite at intervals of $0.5 \mathrm{~cm}$ using a stainless steel cutter. All samples were packed in aluminum foil and were stored at $4{ }^{\circ} \mathrm{C}$ in a car refrigerator during transportation, and then they were kept frozen at $-20^{\circ} \mathrm{C}$ in the laboratory.

\subsection{Sediment characterization}

The samples were analyzed for water content and wet bulk density, from which the porosity and dry bulk density were calculated. Organic matter (OM) content of each section was determined gravimetrically by loss on ignition (LOI) at $550{ }^{\circ} \mathrm{C}$ for $4 \mathrm{~h}$.

A sediment core from each lake was analyzed for ${ }^{210} \mathrm{~Pb},{ }^{226} \mathrm{Ra}$, ${ }^{137} \mathrm{Cs}$ and ${ }^{241} \mathrm{Am}$ by direct measuring radioactivity using $\gamma$-ray spectroscopy in the Environmental Radiometric Facility at University College London, using an ORTEC HP Ge GWL series well-type coaxial low background intrinsic germanium detector. The detailed radiometric dating method is described in the previous work (Yang et al., 2010). Sediment ages and mass sedimentation rates (MSR) were calculated using constant rate of supply (CRS) model. The sediment focusing factor (FF), which was needed to evaluate the post-depositional horizontal movement of the sediment particles, was calculated as the ratio of the unsupported ${ }^{210} \mathrm{~Pb}$ inventory in the sediments in the coring location to that expected from the regional atmospheric input (Yang et al., 2010) and the results are included in Table 1.

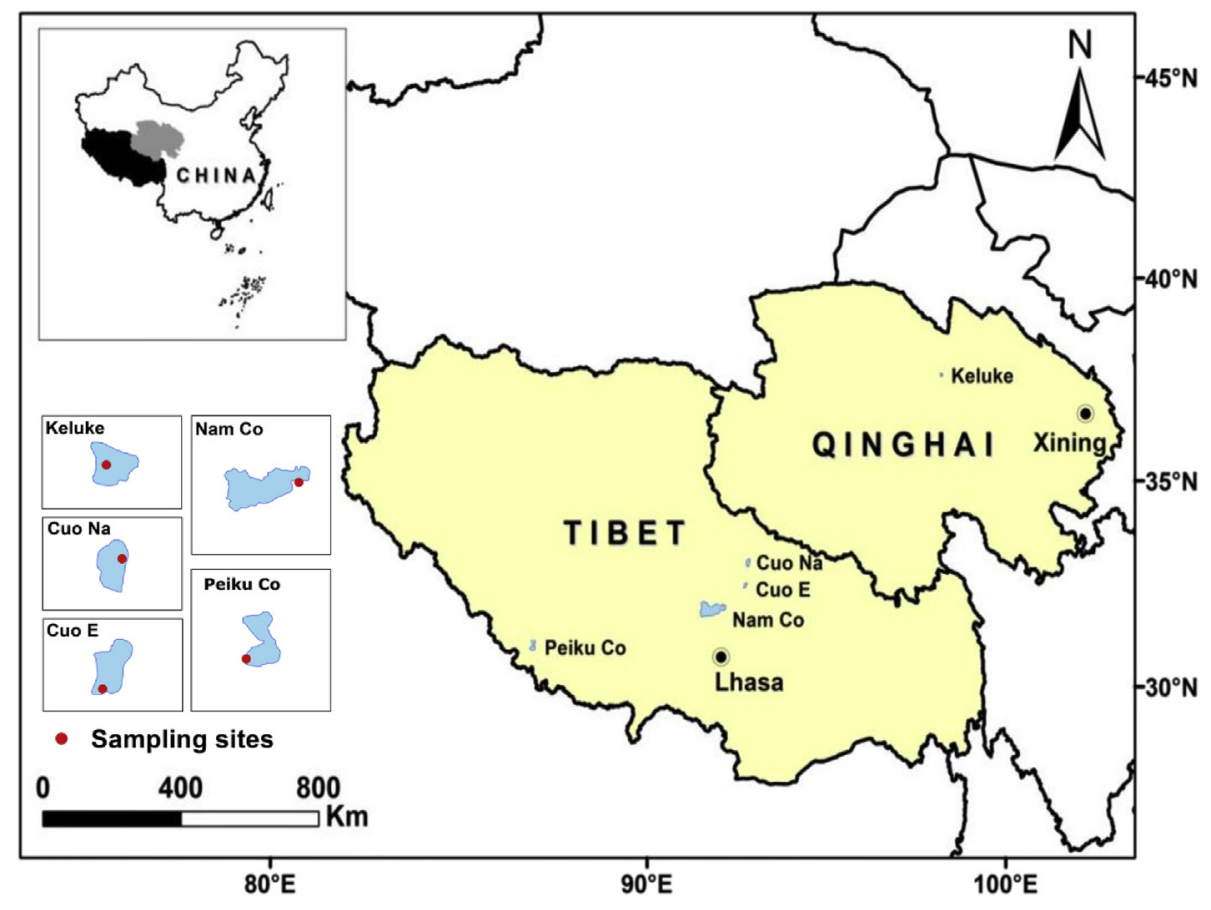

Fig. 1. Map showing locations of the lakes cored for this study. 
Table 1

Lake characteristics, geographic coordinates and focusing factor (FF) in the studied lakes.

\begin{tabular}{|c|c|c|c|c|c|c|c|c|}
\hline Lakes & Latitude $(\mathrm{N})$ & Longitude (E) & Lake altitude (m) & Lake area ${ }^{\mathrm{a}}\left(\mathrm{km}^{2}\right)$ & Salinity $^{\mathrm{b}}\left(\mathrm{Cl}^{-} \mathrm{mg} / \mathrm{L}\right)$ & Core length $(\mathrm{cm})$ & Core water depth (m) & Focusing factor ${ }^{c}$ \\
\hline Keluke & $37^{\circ} 17.165^{\prime}$ & $96^{\circ} 52.922^{\prime}$ & 2813 & 57 & fresh (116.5) & 25.0 & 8.3 & 0.72 \\
\hline Cuo Na & $32^{\circ} 02.921^{\prime}$ & $91^{\circ} 30.805^{\prime}$ & 4617 & 182 & fresh (8.98) & 43.0 & 12.4 & 5.97 \\
\hline Cuo E & $31^{\circ} 25.221^{\prime}$ & $91^{\circ} 29.087^{\prime}$ & 4531 & 61 & brackish (892) & 29.5 & 8.4 & 6.26 \\
\hline Nam Co & $30^{\circ} 46.203^{\prime}$ & $90^{\circ} 55.715^{\prime}$ & 4630 & 1982 & fresh (166) & 42.0 & 21.6 & 1.58 \\
\hline Peiku Co & $28^{\circ} 48.726^{\prime}$ & $85^{\circ} 31.015^{\prime}$ & 4595 & 284 & fresh (103) & 24.5 & 16.3 & 0.17 \\
\hline
\end{tabular}

a (Xiang and Zheng, 1989).

b (Lami et al., 2010).

c (Yang et al., 2010).

\subsection{Chemical analysis}

A PAH mixture standard, a surrogate mixture standard, and the internal standard 2-fluorobiphenyl were purchased from Accustandard (New Haven, CT). The PAH mixture standard contained 16 individual compounds including naphthalene (NAP), acenaphthylene (ACY), acenaphthene (ACP), fluorene (FLR), phenanthrene (PHE), anthracene (ANT), fluoranthene (FLT), pyrene (PYR), benz $a]$ anthracene (BaA), chrysene (CHR), benz[ $b]$ fluoranthene (BbF), benz $[k]$ fluoranthene $(\mathrm{BkF})$, benz $[a]$ pyrene $(\mathrm{BaP})$, indeno[1,2,3-cd]pyrene (IcdP), dibenzo[a,h]anthracene (DahA), and benzo[ghi]perylene(BghiP). The surrogate mixture standard had five deuterated PAHs including naphthalene-d8 (NAP-d8), acenaphthene-d10 (ACP-d10), phenanthrene-d10 (PHE-d10), chrysene-d12 (CHRd12) and perylene-d12 (PER-d12).

The solvents $n$-hexane and dichloromethane used for extraction and cleanup were ultra residue-analytical grade and were purchased from Fisher Scientific (Andover, USA). Alumina (100-200 mesh, Sigma-Aldrich, USA) and Silica gel (100-200 mesh, Qingdao Marine Chemical, China) were baked at $550{ }^{\circ} \mathrm{C}$ for $12 \mathrm{~h}$ and activated at $180{ }^{\circ} \mathrm{C}$ for $2 \mathrm{~h}$. Anhydrous sodium sulfate was baked at $550{ }^{\circ} \mathrm{C}$ for $4 \mathrm{~h}$. Copper powder (200 mesh, Sinopharm Chemical Reagent Co. Ltd, China) was activated before use.

Freeze-dried and ground sediment samples ( $1 \mathrm{~g})$ were spiked with surrogates and extracted using mixed solvents of hexane and dichloromethane (DCM) (1:1, v/v) by accelerated solvent extraction (Dionex ASE350, U.S.) at a temperature of $150{ }^{\circ} \mathrm{C}$ and a pressure of 1500 psi. Activated copper powder was added to the extract to remove elemental sulfur. The extracts were concentrated to about $1-2 \mathrm{ml}$ by a rotary evaporator. The cleanup was conducted using a glass column packed with $6 \mathrm{~g} \mathrm{3 \%}$ deactivated silica gel, $4 \mathrm{~g} 2 \%$ deactivated alumina and 2-cm-thickness of anhydrous sodium sulfate from bottom to top. The elution was subsequently conducted using $10 \mathrm{ml}$ of hexane and a $50 \mathrm{ml}$ mixture of dichloromethane and hexane $(1: 1, v / v)$. The effluent was concentrated to $0.5 \mathrm{ml}$. Quantitative internal standard (200 ng of 4,4'-difluorobiphenyl) were finally added to the extract before instrumental analysis.

An Agilent-7890 gas chromatograph (GC) equipped with an HP5 MS capillary column $(30 \mathrm{~m} \times 0.25 \mathrm{~mm}$ i.d. $\times 0.25 \mu \mathrm{m}$ film thickness) was used to separate PAHs while a mass spectrometer (MS, Agilent 5975) with electron ionization (EI) was used to analyze PAHs. The oven temperature program was operated as follows: initial $60{ }^{\circ} \mathrm{C}$ for $2 \mathrm{~min}, 6{ }^{\circ} \mathrm{C} / \mathrm{min}$ to $300{ }^{\circ} \mathrm{C}$, and held for a final $10 \mathrm{~min}$. The temperature of the injector was set at $280^{\circ} \mathrm{C}$. Highpurity helium was used as the carrier gas with a constant flow of $1 \mathrm{ml} / \mathrm{min}$. The MS detector was operated at $70 \mathrm{eV}$ and the ion source was set at $300{ }^{\circ} \mathrm{C}$. The quadrupole and interface temperatures were $180{ }^{\circ} \mathrm{C}$ and $300{ }^{\circ} \mathrm{C}$, respectively. The MS detector was operated in selected ion monitoring (SIM) mode.

\subsection{Quality control}

A procedural blank using $\mathrm{Na}_{2} \mathrm{SO}_{4}$ in place of sediment was analyzed in each batch of 11 sediment samples. Only trace levels of targets were detected in blanks, and were subtracted from those in sediment samples. The average recoveries of spiked surrogates in all analyzed samples $(\mathrm{N}=157$ ) were $70-136 \%$ for the five deuterated PAHs. The concentrations reported in this paper were corrected by the surrogate recoveries. One or two segments in each core were analyzed in duplicate, and the average relative percentage differences (RPDs) were in the range of $5.1-31.1 \%$. The method detection limit (MDL) was defined as 3:1 signal-to-noise ratio $(\mathrm{S} / \mathrm{N})$ and ranged $0.01-0.41 \mathrm{ng} / \mathrm{g} \mathrm{dw}$. The instrument performance was routinely checked using quality control standards.

\subsection{Estimation of chemical flux}

Flux stands for the accumulation rate of the chemical analyte. Since concentration may be strongly affected by dilution of detrital matter and water content, flux has been considered as a more meaningful way to assess pollutant inputs than concentration (Elmquist et al., 2007). The flux was estimated by the following equation:

$\operatorname{Flux}_{\mathrm{i}}\left(\mu \mathrm{g} / \mathrm{m}^{2} / \mathrm{yr}\right)=\mathrm{C}_{\mathrm{i}} \times \mathrm{MSR} \times 10 / \mathrm{FF}$

where $C_{i}$ is the dry-weight-based concentration in sediment core segment $\mathrm{i}(\mathrm{ng} / \mathrm{g} \mathrm{dw})$, MSR is mass sedimentation rate $\left(\mathrm{g} / \mathrm{cm}^{2} / \mathrm{yr}\right), \mathrm{FF}$ is the focusing factor (dimensionless), reflecting the postdepositional horizontal movement of sediment particles on the lake bottom due to turbulence. The FF value was calculated as the ratio of unsupported ${ }^{210} \mathrm{~Pb}$ accumulation in a core to that atmospheric ${ }^{210} \mathrm{~Pb}$ deposition flux in lake basin soil. Detailed information was described by Yang et al. (2010).

\section{Results and discussion}

\subsection{Concentrations}

The concentrations of total PAHs $\left(\Sigma_{16} \mathrm{PAH}\right)$ in the sediment cores of the five lakes ranged from 98 to $595 \mathrm{ng} / \mathrm{g}$. The $\Sigma_{16} \mathrm{PAH}$ concentration profiles in the cores varied among lakes (Fig. 2A). The PAH concentrations in this study were compared with those sediments from other remote lakes (Table 2). The PAH concentrations were generally higher than those reported previously for sediments from the Arctic (27-140 ng/g, $\Sigma_{15} \mathrm{PAH}$ excluding benz(a)anthracene) (Jiao et al., 2009), the Antarctic (1.4-205 ng/g) (Klanova et al., 2008) and Rocky Mountains (31-280 ng/g) (Usenko et al., 2007). The average $\Sigma_{15} \mathrm{PAH}$ (176 ng/g, excluding naphthalene) in the sediments of this study was approximately double that from the southern slope of the Himalayas in Nepal $(68 \pm 22 \mathrm{ng} / \mathrm{g}$ ) (Guzzella et al., 2011). The PAH concentrations in this study were in the same 

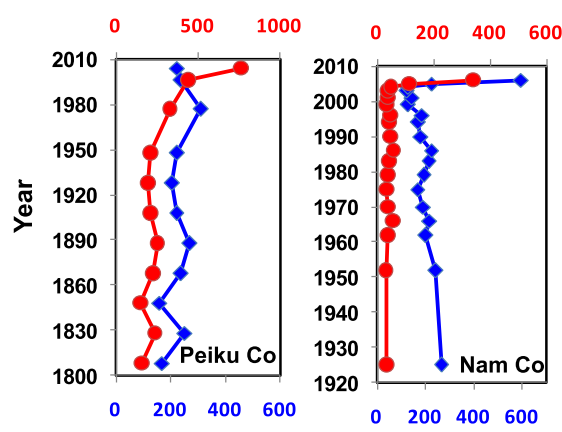

$$
\text { Flux }\left(\mu \mathrm{g} \mathrm{m}^{-2} \mathrm{yr}^{-1}\right)
$$
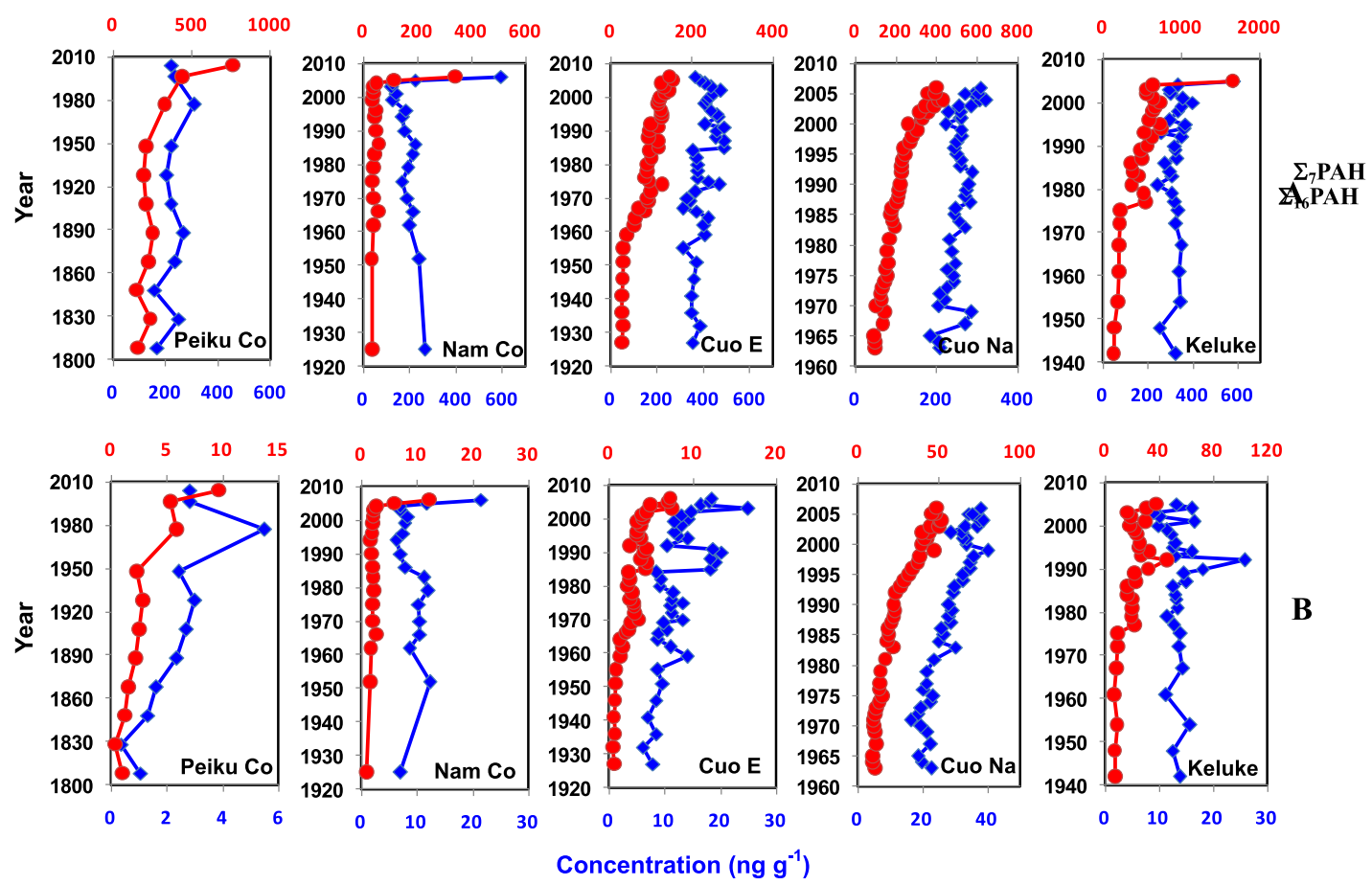

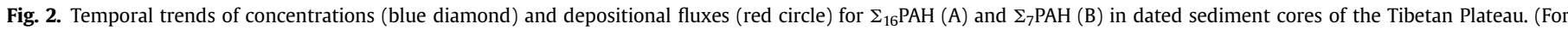
interpretation of the references to colour in this figure legend, the reader is referred to the web version of this article.)

Table 2

Comparison of PAH concentrations (ng/g dw) in sediments from remote lakes.

\begin{tabular}{|c|c|c|c|c|c|}
\hline Location & Sampling year & Sediment type & Concentration & No. of congener ${ }^{a}$ & Reference \\
\hline Mountain lakes, across TP & $2006-07$ & core & $98-594$ & $\sum_{16} \mathrm{PAH}^{\mathrm{b}}$ & This study \\
\hline Qinhai Lake, northern TP & 2006 & core & $11-279$ & $\sum_{15} \mathrm{PAH}^{\mathrm{c}}$ & (Wang et al., 2010) \\
\hline Southern Himalaya lakes, Nepal & 2007 & surface & $68 \pm 22$ & $\sum_{15} \mathrm{PAH}^{\mathrm{c}}$ & (Guzzella et al., 2011) \\
\hline Andean mountain lakes, Chile & 2002 & core & $32-862$ & $\sum_{16} \mathrm{PAH}$ & (Barra et al., 2006) \\
\hline High Tatras, Eastern Europe & 2001 & surface & $1800-30000$ & $\sum_{15} \mathrm{PAH}^{\mathrm{d}}$ & (van Drooge et al., 2011) \\
\hline Remote lake, north-west Scotland & 1996 & core & $626-1719$ & $\sum_{16} \mathrm{PAH}$ & (Rose and Rippey, 2002) \\
\hline Rocky Mountain, North America & 2003 & core & $31-280$ & $\sum_{16} \mathrm{PAH}$ & (Usenko et al., 2007) \\
\hline Ny-Alesund lakes, Norway Arctic & 2005 & surface & $27-140$ & $\sum_{15} \mathrm{PAH}^{\mathrm{e}}$ & (Jiao et al., 2009) \\
\hline James Ross Island, Anarctic & 2005 & surface & $1.4-205$ & $\sum_{16} \mathrm{PAH}$ & (Klanova et al., 2008) \\
\hline
\end{tabular}

${ }^{a}$ The PAH levels selected for comparison were chosen from the studies having similar compound groupings.

b Sum of 16 US EPA priority PAHs.

c 16 US EPA PAHs excluding naphthalene.

d 16 US EPA PAHs excluding naphthalene, acenaphthene and acenaphthylene plus perylene and benzo $(e)$ pyrene.

e 16 US EPA PAHs excluding benza( $a$ )anthracene.

order of magnitude with those reported in sediment from the Andes mountains (32-862 ng/g) (Barra et al., 2006) but 1-2 orders of magnitude lower than those in sediments from European mountains (Rose and Rippey, 2002; van Drooge et al., 2011). The elevated concentrations in the TP might be due to its proximity to possible source regions. The lakes in this study, especially in the southern and central areas, are located at altitude over $4500 \mathrm{~m}$ a.s.l. and are likely to be in the free troposphere. Deposited PAHs at these altitudes is likely to be derived from LRAT sources, most probably from Indian subcontinent and China inland areas. Precipitation on the TP is strongly controlled by the Asian monsoon system (Pant and Rupa Kumar, 1997). Studies have documented that the transport and fate of contaminants to TP are likely to be significantly influenced by regional monsoon systems (Yang et al., 2008, Wang et al., 2008 Yang et al., 2010).

The 16 PAHs were grouped into 2\&3-rings (NAP, ACY, ACP, FLR,
PHE and ANT), 4-ring (FLT, PYR, BaA and CHR) and 5\&6-rings (BbF, BkF, BaP, IcdP, DahA, and BghiP). Because high molecular weight PAHs are mostly generated from high temperature combustion, such as in coke ovens and diesel engines (Mai et al., 2003), the sum of the 5 and 6-ring PAHs $\Sigma_{7} \mathrm{PAH}$ (BaA, CHR, BbF, BkF, BaP, IcdP and DahA) is a good indicator in reflecting the impacts of industrial and traffic emissions. In this study, the increasing trends of $\Sigma_{7} \mathrm{PAH}$ are even clearer than $\Sigma_{16} \mathrm{PAH}$ in all studied lakes (Fig. 2B). Therefore, the $\Sigma_{7} \mathrm{PAH}$ can be a more appropriate parameter to reflect the anthropologic impacts by human activities on the TP.

\subsection{Deposition flux and historical trends}

Differing with concentration profiles in cores, fluxes calculated by considering variation in sedimentation rate, show a general increasing trend from the deeper layers towards the upper layer 
sediments (Fig. 2). The PAH fluxes were low with little variability before the 1950s, and then gradually increased from the 1950s to the late 1980s, and the increase appears to have accelerated from the 1990s. This temporal pattern is clearly different from those found in remote mountain lakes across Europe, where the pyrolytic PAHs peaked in the 1960s-1980s (Fernandez et al., 2000). The period (from the 1960s to the 1980s) during which PAHs started to decrease in the developed countries is when PAH emissions started to increase rapidly in the surroundings of the TP, as observed in the present study. The difference of the temporal trend was attributed to differences in the economic development stages and energy structure between the early industrialized and newly industrialized countries.

Nevertheless, the vertical profile of PAH flux is somewhat different among individual lakes. The temporal resolution of Peiku Co is relatively poor due to its low sedimentation rate; but on the other hand, this allows observing a temporal trend of accumulation covering more than $200 \mathrm{yrs}$. In addition, it is notable that temporal profile in Nam Co seems relatively stable since 1950 until post2000, differing with other studied lakes (Fig. 2). The Nam Co Core was taken in a bay in the southeast of the lake and un-decomposed algal gel appeared above ca. $20 \mathrm{~cm}$ (Fig. S1). The abundance of the algae increased significantly upwards to the sediment surface (organic matter content from $14.7 \%$ at $20 \mathrm{~cm}$ to $27.4 \%$ in the surface). Correlation analysis between $\Sigma_{16} \mathrm{PAH}$ concentration and organic matter content showed significantly negative correlation (correlation coefficient $R=-0.593, P=0.012$ ), indicating the possible dilution role of algae on PAH concentrations in sediment, which was also confirmed by Yang et al. (2010) that mercury concentration was diluted by algae in Nam Co Lake. Differences between these sites may be attribute to the locations of lakes of the plateau with different meteorological conditions and proximity to sources.

\subsection{Implications for sources}

Fig. 3 clearly shows that the low molecular weight PAHs (2-3 rings) are dominant in the sediments of the TP with an average percentage over $87 \%$. This is considerably different from the patterns in source regions of the South China Sea (Liu et al., 2012a,b) where high molecular weight PAHs dominate. The lighter PAHs are more easily transported to the remote TP through LRAT, which might be an explanation to the dominance of low molecular weight PAHs (Tao et al., 2011; Yang et al., 2013). In addition, biomass burning, which is commonly used heating source in the TP, produces more lighter PAHs. In contrast to this, within more developed regions, industrial and traffic related combustion emits higher proportions of heavier PAHs (Bhatt and Sachan, 2004).

Temporal variations in PAH compositions have been used as an indicator of a shift in PAH sources (Liu et al., 2012a). The percentage of heavier PAHs (4-6 rings) increased in recent years in most of the lakes of this work (Fig. 3). In particular, the fractions of 5-ring BbF, which is a known product of high-temperature combustion (Mai et al., 2003), and 6-ring IcdP and BghiP, which are tracers of vehicle exhaust (Harrison et al., 1996), have increased 2.0 and 3.5 fold, respectively, since the year 1990 in Cuo Na lake (Fig. 4A). The concentration profiles show similarly increasing trends with fluxes (Fig. S2). These observations suggest the increasing contribution of local, high-temperature combustion sources in the past decade, when Tibet has experienced exponential growths in population, tourism, and gross industrial activities (Fig. 4B). The remarkable increase of IcdP and BghiP concentrations (tracers of vehicle exhaust) in Cuo Na Lake possibly resulting from the rapid increasing emissions by traffic and transportation in recent years due to its relatively close to the Qinghai-Tibet highway and Qinghai-Tibet Railway. The variation of PAH pattern in sediment is an evidence that the rapid social economical changes in Tibet have impacted its previously pristine ecosystem. These concerns have been raised from other studies (Wang et al., 2010; Yang et al., 2010; Cong et al., 2013).

Diagnostic concentration fractions of PAH isomers, such as ANT/ (ANT + PHE), BaA/(BaA + CHR), FLT/(FLT + PYR) and IcdP/ (IcdP + BghiP) are often applied for source identification purposes (Yunker et al., 2002; Liu et al., 2012b). ANT and BaA are believed to be more susceptible to photochemical degradation than their isomers (Behymer and Hites, 1988; Zhang et al., 2005; Liu et al., 2012b). However, the FLT/PYR and IcdP/BghiP isomer pairs were diluted and degraded at analogous rates, so the ratios of FLT/ (FLT + PYR) and IcdP/(IcdP + BghiP) might be more suitable for defining sources of PAHs in remote areas like TP. In this study, most of the measured ratios of IcdP/(IcdP + BghiP) and FLT/(FLT + PYR) were greater than 0.2 and 0.4 , respectively (Fig. 5). According to the source classification by Yunker et al. (2002), the sources of PAHs in the sediments are mainly from grass, biomass \& coal combustion. The vertical patterns of the investigated congeners were relatively consistent and without any general trends throughout the whole length of the cores, apart from the decrease in the ratios of IcdP/ $($ IcdP + BghiP) in the superficial segments of Cuo Na Lake (Fig. S3).
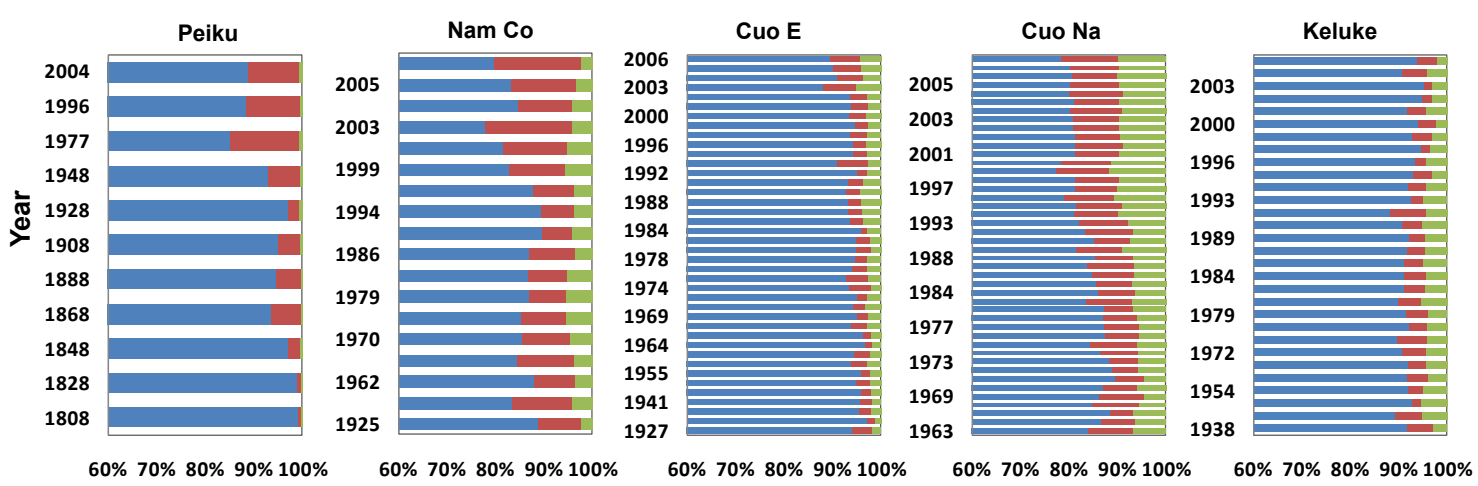

$=2 \& 3$ ring $\| 4$ ring $=5 \& 6$ ring

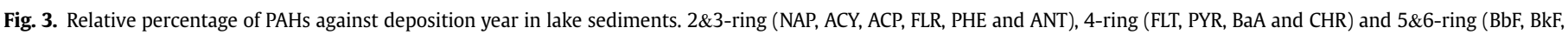
BaP, IcdP, DahA and BghiP). 

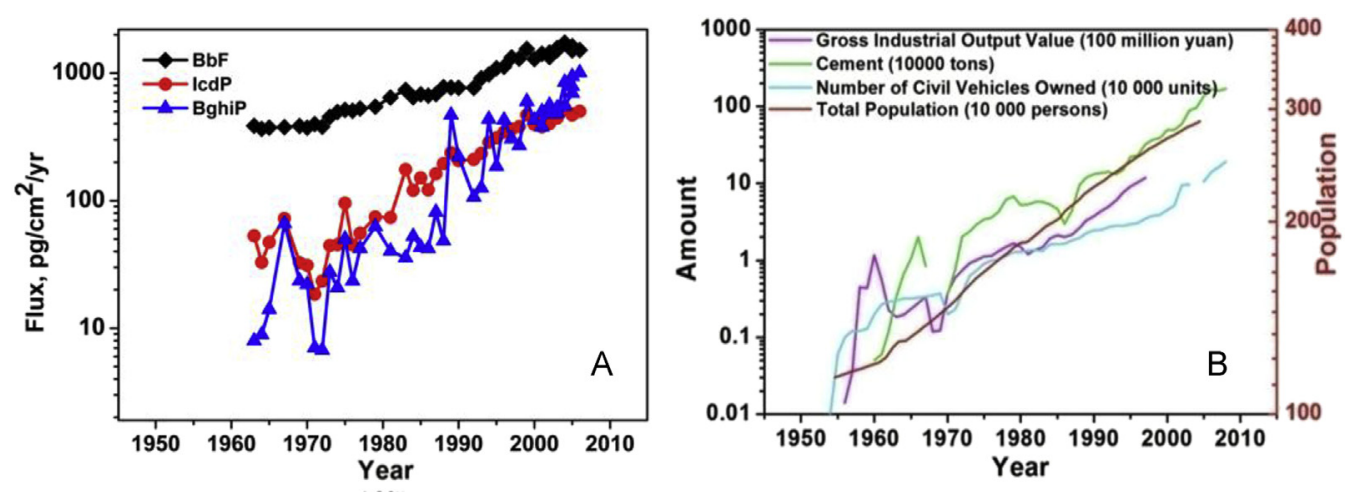

Fig. 4. Deposition fluxes of selected PAHs in Lake Cuo $\mathrm{Na}(\mathrm{A})$ and population and economic development data of Tibet* (B).

*Data from NBSC. China Statistical Yearbook 1949-2008; China Statistics Press, Beijing.

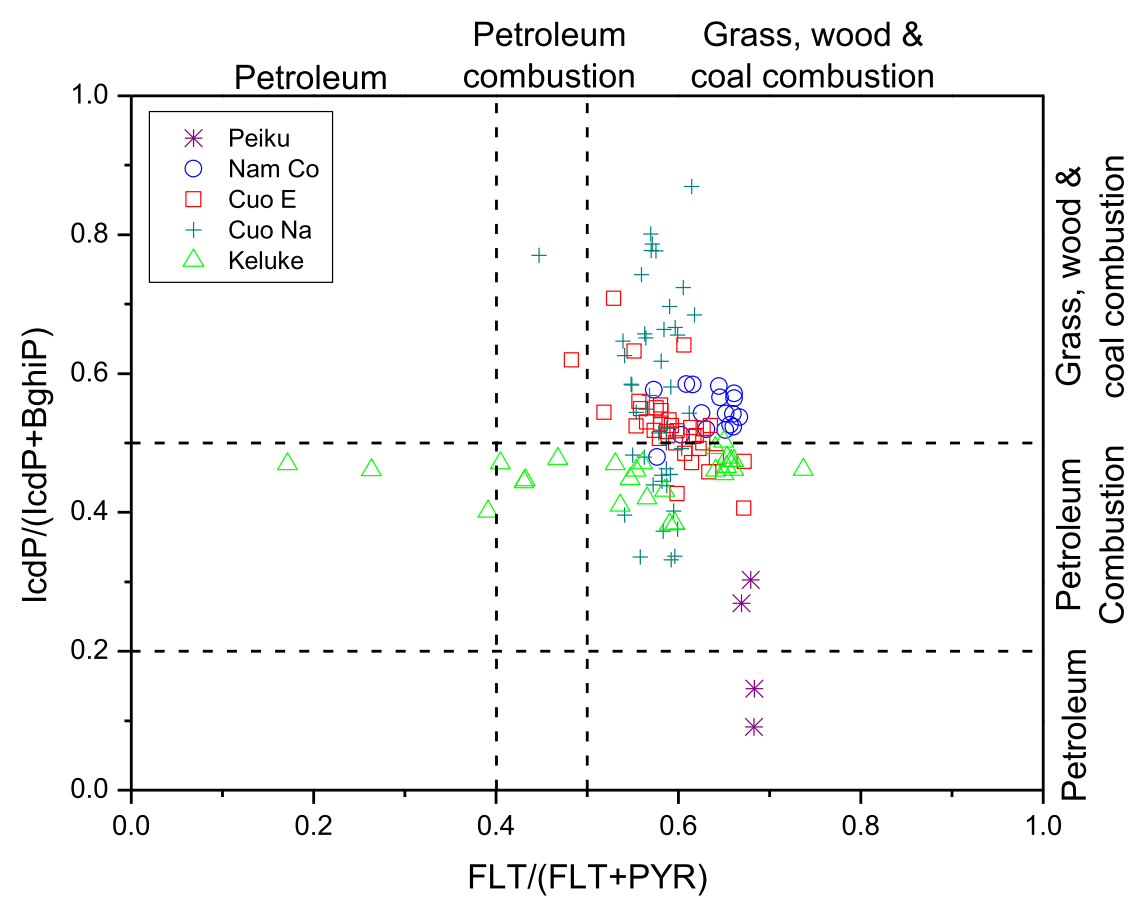

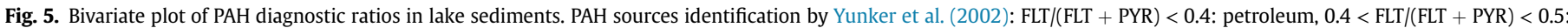

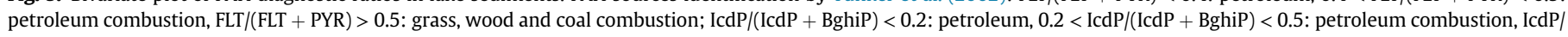
$($ IcdP + BghiP) $>0.5$ : grass, wood and coal combustion.

\section{Conclusion}

In this study, five sediment cores across the TP were analyzed for PAHs with the objective examining their time trends. The depositional flux of PAHs generally showed an increasing trend from the deeper layers towards the upper layer sediments, with a faster increasing rate after the 1990s, which were apparently different from those reported in European mountains. The dominant of lighter PAHs indicates they are mainly from grass, biomass \& coal combustion and/or from LRAT. Particular concern is the recent shift in PAH sources. The percentage of heavier PAH (4-6 rings) increased rapidly in the past two decades suggest increasing contribution of local, high-temperature combustion sources in the TP.

\section{Acknowledgements}

This work was financially supported by the National Natural Science Foundation of China (21277167, 21577164 and 41073093) and the Leverhulme Trust project "Lake sediment evidence for long-range air pollution on the Tibetan Plateau" (Project F/ 07134BF).

\section{Appendix A. Supplementary data}

Supplementary data related to this article can be found at http:// dx.doi.org/10.1016/j.envpol.2016.03.068.

\section{References}

Barra, R., Popp, P., Quiroz, R., Treutler, H.C., Araneda, A., Bauer, C., Urrutia, R., 2006 Polycyclic aromatic hydrocarbons fluxes during the past 50 years observed in dated sediment cores from Andean mountain lakes in central south Chile. 
Ecotoxicol. Environ. Saf. 63, 52-60.

Behymer, T.D., Hites, R.A., 1988. Photolysis of polycyclic aromatic hydrocarbons adsorbed on fly ash. Environ. Sci. Technol. 22, 1311-1319.

Bettinetti, R.S., Galassi, S., Guilizzoni, P., Quadroni, S., 2011. Sediment analysis to support the recent glacial origin of DDT pollution in Lake Iseo (Northern Italy). Chemosphere 85, 163-169.

Bhatt, B.P., Sachan, M.S., 2004. Firewood consumption along an altitudinal gradient in mountain villages of India. Biomass Bioenergy 27, 69-75.

Bogdal, C., Schmid, P., Kohler, M., Muller, C.E., Iozza, S., Bucheli, T.D., Scheringer, M., Hungerbuhler, K., 2009. Blast from the past: melting glaciers as a relevant source for persistent organic pollutants. Environ. Sci. Technol. 43, 8173-8177.

Cheng, H.R., Lin, T., Zhang, G., Liu, G.Q., Zhang, W.L., Qi, S.H., Jones, K.C., Zhang, X.W. 2014. DDTs and HCHs in sediment cores from the Tibetan Plateau. Chemosphere 94, 183-189.

Cong, Z.Y., Kang, S.C., Gao, S.P., Zhang, Y.L., Li, Q., Kawamura, K., 2013. Historical trends of atmospheric black carbon on Tibetan Plateau as reconstructed from a 150-year lake sediment record. Environ. Sci. Technol. 47, 2579-2586.

Elmquist, M., Zencak, Z., Gustafsson, Ö., 2007. A 700 year sediment record of black carbon and polycyclic aromatic hydrocarbons near the EMEP air monitoring station in Aspvreten, Sweden. Environ. Sci. Technol, 41, 6926-6932.

Fernandez, P., Vilanova, R.M., Martinez, C., Appleby, P., Grimalt, J.O., 2000. The historical record of atmospheric pyrolytic pollution over Europe registered in the sedimentary PAH from remote mountain lakes. Environ. Sci. Technol. 34, 1906-1913.

Guzzella, L., Poma, G., De Paolis, A., Roscioli, C., Viviano, G., 2011. Organic persistent toxic substances in soils, waters and sediments along an altitudinal gradient at Mt. Sagarmatha, Himalayas, Nepal. Environ. Pollut. 159, 2552-2564.

Han, Y.M., Wei, C., Bandowe, B.A.M., Wilcke, W., Cao, J.J., Xu, B.Q., Gao, S.P., Tie, X.X. Li, G.H., Jin, Z.D., An, Z.S., 2015. Elemental carbon and polycyclic aromatic compounds in a 150-year sediment core from Lake Qinghai, Tibetan Plateau, China: influence of regional and local sources and transport pathways. Environ. Sci. Technol. 49, 4176-4183.

Harrison, R.M., Smith, D.J.T., Luhana, L., 1996. Source apportionment of atmospheric polycyclic aromatic hydrocarbons collected from an urban location in Birmingham, UK. Environ. Sci. Technol. 30, 825-832.

Jiao, L.P., Zheng, G.J., Minh, T.B., Richardson, B., Chen, L.Q., Zhang, Y.H., Yeung, L.W. Lam, J.C.W., Yang, X.L., Lam, P.K.S., Wong, M.H., 2009. Persistent toxic substances in remote lake and coastal sediments from Svalbard, Norwegian Arctic: levels, sources and fluxes. Environ. Pollut. 157, 1342-1351.

Juttner, I.B., Henkelmann, B., Schramm, K.W., Steinberg, C.E.W., Winkler, R. Kettrup, A. 1997. Occurrence of PCDD/F in dated lake sediments of the Black Forest, southwestern Germany. Environ. Sci. Technol. 31, 806-812.

Klanova, J.N., Matykiewiczova, N., Macka, Z., Prosek, P., Laska, K., Klan, P., 2008 Persistent organic pollutants in soils and sediments from James ROSS Island, Antarctica. Environ. Pollut. 152, 416-423.

Lami, A., Turner, S., Musazzi, S., Gerli, S., Guilizzoni, P., Rose, N.L., Yang, H.D., Wu, G.J., Yang, R.Q., 2010. Sedimentary evidence for recent increases in production in Tibetan plateau lakes. Hydrobiologia 648, 175-187.

Liu, L.Y., Wang, J.Z., Wei, G.L., Guan, Y.F., Wong, C.S., Zeng, E.Y., 2012a. Sediment records of polycyclic aromatic hydrocarbons (PAHs) in the continental shelf of China: implications for evolving anthropogenic impacts. Environ. Sci. Technol. 46, 6497-6504.

Liu, L.Y., Wang, J.Z., Wei, G.L., Guan, Y.F., Zeng, E.Y., 2012b. Polycyclic aromatic hydrocarbons (PAHs) in continental shelf sediment of China: implications for anthropogenic influences on coastal marine environment. Environ. Pollut. 167, 155-162.

Mai, B.X., Qi, S.H., Zeng, E.Y., Yang, Q.S., Zhang, G., Fu, J.M., Sheng, G.Y., Peng, P.N., Wang, Z.S., 2003. Distribution of polycyclic aromatic hydrocarbons in the coastal region off Macao, China: assessment of input sources and transport pathways using compositional analysis. Environ. Sci. Technol. 37, 4855-4863.

NBSC. China Statistical Yearbook 1949-2008; China Statistics Press, Beijing.

Nie, Y., Zhang, Y.L., Ding, M.J., Liu, L.S., Wang, Z.F., 2013. Lake change and its implication in the vicinity of Mt. Qomolangma (Everest), central high Himalayas, 1970-2009. Environ. Earth Sci. 68, 251-265.

Pant, G.B., Rupa Kumar, K., 1997. Climates of South Asia. John Wiley and Sons, Chichester.

Rose, N.L., Rippey, B., 2002. The historical record of PAH, PCB, trace metal and flyash particle deposition at a remote lake in north-west Scotland. Environ. Pollut. 117, 121-132.

Tao, S., Wang, W.T., Liu, W.X., Zuo, Q.A., Wang, X.L., Wang, R., Wang, B., Shen, G.F., Yang, Y.H., He, J.S., 2011. Polycyclic aromatic hydrocarbons and organochlorine pesticides in surface soils from the Qinghai-Tibetan plateau. J. Environ. Monit. 13, 175-181.

Usenko, S., Landers, D.H., Appleby, P.G., Simonich, S.L., 2007. Current and historical deposition of PBDEs, pesticides, PCBs, and PAHs to rocky mountain national park. Environ. Sci. Technol. 41, 7235-7241.

van Drooge, B.L., Lopez, J., Fernandez, P., Grimalt, J.O., Stuchlik, E., 2011. Polycyclic aromatic hydrocarbons in lake sediments from the High Tatras. Environ. Pollut. $159,1234-1240$

Wang, X.P., Xu, B.Q., Kang, S.C., Cong, Z.Y., Yao, T.D., 2008. The historical residue trends of DDT, hexachlorocyclohexanes and polycyclic aromatic hydrocarbons in an ice core from Mt. Everest, central Himalayas, China. Atmos. Environ. 42, 6699-6709.

Wang, X.P., Yang, H.D., Gong, P., Zhao, X., Wu, G.J., Turner, S., Yao, T.D., 2010. One century sedimentary records of polycyclic aromatic hydrocarbons, mercury and trace elements in the Qinghai Lake, Tibetan Plateau. Environ. Pollut. 158, 3065-3070.

Xiang, J., Zheng, M.P., 1989. Saline Lakes on the Qinghai-Tibet Plateau. Beijing Science \& Technology Press, Beijing.

Yang, H., Battarbee, R.W., Turner, S.D., Rose, N.L., Derwent, R.G., Wu, G.J., Yang, R.Q. 2010. Historical reconstruction of mercury pollution across the Tibetan Plateau using lake sediments. Environ. Sci. Technol. 44, 2918-2924.

Yang, R.Q., Yao, T.D., Xu, B.Q., Jiang, G.B., Zheng, X.Y., 2008. Distribution of organochlorine pesticides (OCPs) in conifer needles in the southeast Tibetan Plateau. Environ. Pollut. 153, 92-100.

Yang, R.Q., Zhang, S.J., Li, A., Jiang, G.B., Jing, C.Y., 2013. Altitudinal and spatial signature of persistent organic pollutants in soil, lichen, conifer needles, and bark of the southeast Tibetan Plateau: implications for sources and environmental cycling. Environ. Sci. Technol. 47, 12736-12743.

Yunker, M.B., Macdonald, R.W., Vingarzan, R., Mitchell, R.H., Goyette, D., Sylvestre, S., 2002. PAHs in the Fraser River basin: a critical appraisal of PAH ratios as indicators of PAH source and composition. Org. Geochem. 33, 489-515.

Zhang, X., Tao, S., Liu, W.X., Yang, Y., Zuo, Q., Liu, S.Z., 2005. Source diagnostics of polycyclic aromatic hydrocarbons based on species ratios: a multimedia approach. Environ. Sci. Technol. 39, 9109-9114. 